\title{
THE REVIEW/DEVELOPMENT OF THE AUSTRALIAN AND NEW ZEALAND STANDARD CLASSIFICATION OF OCCUPATIONS (ANZSCO)
}

\author{
Andrew Hancock \\ Classifications and Standards Section \\ Statistics New Zealand
}

\begin{abstract}
Statistics New Zealand and the Australian Bureau of Statistics are undertaking a joint project to produce a new Australian and New Zealand Standard Classification of Occupations (ANZSCO). This paper will discuss the reasons and background for the project. In addition there will be discussion on the use of skill level and skill specialisation as conceptual criteria and how this is utilised to produce an intuitive classification structure. The paper will also look at the issues being faced by both statistical agencies to produce a relevant 'real-world' classification that ensures that contemporary and future user needs are met.
\end{abstract}

\section{Background}

The project for the development of the Australian and New Zealand Standard Classification of Occupations (ANZSCO) was first discussed at a user workshop in Wellington in 1993. At that time, Statistics New Zealand (Statistics NZ) was considering reviewing the New Zealand Standard Classification of Occupations (NZSCO) and the Australian Bureau of Statistics (ABS) was beginning to develop the Australian Standard Classification of Occupations (ASCO) Second Edition. To facilitate closer working relations and to utilise resources and knowledge that exist in both agencies, Statistics NZ and the ABS have an agreed policy to harmonise classifications wherever practical. Consequently it was felt, in 1993, that the time was appropriate to consider developing a joint Australian and New Zealand Standard Classification of Occupations.

A major consideration in proposing a joint classification was the benefit that would come about for users of occupational data as they would then be able to make better comparisons of the Australian and New Zealand labour markets. A joint classification would also enable comparable census data to be produced using a single classification framework. At the time of the 1993 workshop it was recognised that despite the similarities between Australia and New Zealand in terms of labour market shifts, and education and training reforms, there were still some significant issues at that time which prevented the development of a harmonised classification. Further, there was concern that there was insufficient time to produce a harmonised classification in time for the 1996 Census of Population and Dwellings. The agreement made at the 1993 workshop was that both agencies update and maintain their occupation classifications and work towards producing a harmonised classification for the 2006 Census of Population and Dwellings.
At the end of 2001 Statistics NZ and the ABS began discussing the feasibility of producing a joint Australian and New Zealand Standard Classification of Occupations. It was recognised that similarities between the Australian and New Zealand labour markets such as increased Trans-Tasman migration, the development of an increasingly homogeneous labour market and the similarity in education and training practices had created an environment conducive to developing a harmonised classification.

In addition to this favourable environment, Statistics NZ further recognised that (1) the New Zealand Standard Classification of Occupations (NZSCO) had not had a major review since 1988; (2) labour market changes meant that the current NZSCO classification structure would compromise the production of meaningful occupation data past 2006; (3) technological and skill changes were impacting on all occupations and this needed to be reflected in the classification; and (4) growth areas of the economy and real world changes were not being adequately dealt with.

A further consideration that Statistics NZ had to consider was when the review of the International Standard Classification of Occupations (ISCO) would take place. The NZSCO has always been based on the ISCO structure modified to New Zealand conditions and the International Labour Office was indicating that the ISCO review would not take place until 2008. This was deemed too long a period to wait before undertaking a major review.

A major advantage of undertaking the ANZSCO project was the opportunity that it gave for the ABS and Statistics NZ to produce an occupation classification that could influence the direction of the international community and particularly influence the direction of the 2008 edition of ISCO. 
As a result, Statistics NZ sought New Zealand users approval to begin work with the ABS to develop a new occupation classification. Three options were put forward to users to consider. These were:

1. structure;

2. conducting a major review without harmonising with Australia;

3. conducting a major review and harmonising with Australia.

New Zealand users gave their approval to option three as harmonising with Australia provided the most benefits for users. In addition Statistics NZ gave a guarantee that the 2006 Census of Population and Dwellings would dualcode (ie code to both NZSCO and ANZSCO) the occupation question so that a time-series dataset would be available.

\section{Development of the Classification}

An ANZSCO project was set up between both statistical agencies and the Australian Department of Employment and Workplace Relations (DEWR), as they had worked closely with the ABS in producing ASCO Second Edition.

The project team then set about the process of developing some conceptual models for ANZSCO for users to consider. Extensive investigation of existing occupational classification practices around the world took place. Consideration was given to following the conceptual approaches taken by (a) North America, particularly the approach taken in Canada with the National Occupational Classification (NOC); (b) the European Union and the modificd ISCO88 classification; and (c) the United Kingdom's Standard Occupational Classification. All three approaches used different applications of skill criteria to form the framework for the classifications.

Conceptual models developed for user consultation were as follows:

An approach similar to ASCO Second Edition with skill level criterion applied primarily at the major group level of the classification. Skill specialisation was used to differentiate between major groups at the same skill level and skill specialisation was applied in progressively finer degrees of detail in the lower levels of the classification.

An approach using a combination of skill level and skill specialisation to design major groups. Skill level was then applied rigorously at the sub-major group level. All submajor groups would be at one skill level.

An approach similar to option 2 to design the major groups. Skill level and skill specialisation are used at the sub-major and minor group levels to form meaningful groups in terms of type of work performed. Skill level was then applied rigorously at the unit group level.

The outcome of user consultation indicated that option two with some aspects of option three was the preferred approach for developing the classification.

\section{Conceptual Criteria}

The current NZSCO and the proposed ANZSCO both use the concepts of skill level and skill specialisation to create the structural framework of the classifications. NZSCO uses four skill levels (based upon educational requirements) as the first criteria for where an occupation is placed within the classification structure. Each of the nine NZSCO major groups is based around a general qualification requirement such as a university degree, national certificate, trade certificate or on the job training. Where on the job training is the primary qualification, major groups have been developed upon areas of user interest ie creating a major group specifically for all agricultural occupations, all clerical occupations or all sales and service occupations.

ANZSCO takes a different approach. Skill level is applied more rigorously at the two-digit sub-major group level. The intention is that a sub-major group will be at one skill level only. This means that multiple skill levels will exist within each major group. When a sub-major group contains more than one skill level, this will be fully documented. This may occur because an occupation intuitively sits with similar occupations even though the skill level might be different.

Skill level is defined as a function of the range and complexity of the set of tasks performed in a particular occupation. This is measured operationally by the level of formal education and training, the amount of previous experience and the amount of on the job training required for competent performance.

Skill specialisation is defined as a function of the field of knowledge required, tools and equipment used, materials worked on and goods and services produced.

Aspects of 'generic employability skills' may be included where appropriate to recognise factors such as communication skills, team work, problem solving and planning. Personal attributes will not be included as these are attributes of people rather than jobs. The use of generic employability skills can assist in distinguishing between occupations, however in ANZSCO these will generally be only included in the unit group definitions.

There are five skill levels used in ANZSCO and these are defined in terms of the New Zealand Register of Quality Assured Qualifications and the Australian Qualifications Framework. NZSCO used four skill levels to classify occupations to a major group.

The more rigorous application of skill level at the submajor group level has resulted in the number of major groups changing from NZSCO. ANZSCO contains eight Major Groups and 44 Sub-Major Groups, whereas NZSCO had nine Major Groups and 24 Sub-Major Groups. The ANZSCO classification is a five level hierarchic classification using the same levels as NZSCO ic Major Group, Sub-Major Group, Minor Group, Unit Group and Occupation. ANZSCO uses a six digit code to represent the occupation category whereas NZSCO uses a five digit code. 


\begin{tabular}{|c|c|c|c|}
\hline \multicolumn{2}{|c|}{ NZSCO Major Groups } & \multicolumn{2}{|c|}{ ANZSCO Major Groups } \\
\hline 1 & $\begin{array}{l}\text { Legislators and } \\
\text { Managers }\end{array}$ & 1 & Managers \\
\hline 2 & Professionals & 2 & Professionals \\
\hline 3 & $\begin{array}{ll}\text { Technicians and } \\
\text { Associate } \\
\text { Professionals }\end{array}$ & 3 & $\begin{array}{l}\text { Technicians and Trades } \\
\text { Workers }\end{array}$ \\
\hline 4 & Clerks & 4 & $\begin{array}{lr}\text { Community } & \text { and } \\
\text { Personal } & \text { Service } \\
\text { Workers } & \end{array}$ \\
\hline 5 & $\begin{array}{l}\text { Sales and Service } \\
\text { Workers }\end{array}$ & 5 & $\begin{array}{l}\text { Clerical and } \\
\text { Administrative Workers }\end{array}$ \\
\hline 6 & $\begin{array}{l}\text { Agriculture and } \\
\text { Fishery Workers }\end{array}$ & 6 & Sales Workers \\
\hline 7 & Trades Workers & 7 & $\begin{array}{l}\text { Machinery } \\
\text { and Drivers }\end{array}$ \\
\hline 8 & $\begin{array}{lr}\text { Plant and } & \text { Machine } \\
\text { Operators } & \text { and } \\
\text { Assemblers } & \\
\end{array}$ & 8 & Labourers \\
\hline 9 & $\begin{array}{l}\text { Elementary } \\
\text { Occupations }\end{array}$ & & \\
\hline
\end{tabular}

The five skills used in ANZSCO are defined as follows:

\begin{tabular}{|l|l|}
\hline 1 & $\begin{array}{l}\text { Bachelor degree or higher qualification. At least 5 } \\
\text { years relevant experience may substitute for the } \\
\text { formal qualifications. }\end{array}$ \\
\hline 2 & $\begin{array}{l}\text { NZ Register Diploma. At least 3 years relevant } \\
\text { experience may substitute for the formal } \\
\text { qualification. }\end{array}$ \\
\hline 3 & $\begin{array}{l}\text { NZ Register Level 4 qualification. At least 3 years } \\
\text { relevant experience may substitute for the } \\
\text { qualification. }\end{array}$ \\
\hline 4 & $\begin{array}{l}\text { NZ Register Level 2 or 3 qualification. At least 1 } \\
\text { year of relevant experience may substitute for the } \\
\text { qualification. }\end{array}$ \\
\hline 5 & $\begin{array}{l}\text { NZ Register Level 1 qualification or compulsory } \\
\text { secondary schooling. }\end{array}$ \\
\hline
\end{tabular}

Skill specialisation is applied at all hierarchical levels in ANZSCO to differentiate between categories. At the major group level, skill specialisation is taken into consideration in a broad sense to design intuitively meaningful and useful major groups.

\section{Changes between NZSCO and ANZSCO}

Although both NZSCO and ANZSCO are using the same conceptual criteria, which as seen above has resulted in a different major group structure, there are a number of other differences that should be noted.

\section{Structural Differences}

The following table highlights the structural differences between NZSCO and ANZSCO by showing the numbers at each level of the classification.

Numbers identified at the occupation level are provisional at the time of writing as the classification structure has not been finalised.

\begin{tabular}{|l|l|l|}
\hline & NZSCO & ANZSCO \\
\hline Major Groups & 9 & 8 \\
\hline Sub-Major Groups & 24 & 44 \\
\hline Minor Groups & 97 & 95 \\
\hline Unit Groups & 254 & 343 \\
\hline Occupations & 560 & 892 \\
\hline
\end{tabular}

\section{Alternative Views}

ANZSCO will be providing some alternative output views of the classification. These alternative views are designed to cut across the classification and intended to group together all the occupations in a particular sector from the classification, based upon some conceptual criteria. This means users can identify all the occupations in a particular sector or view of the classification, rather than just having the traditional top-down approach of grouping occupations.

Alternative views will be created for Agriculture, Culture and Leisure, Health and ICT.

\section{Agriculture}

In NZSCO there was a single major group where all agricultural occupations were included. In ANZSCO, the farmers and farm managers have been placed into a single sub-major group in Major Group 1 Managers. Farm workers have been placed into a single sub-major group in Major Group 8 Labourers. Additional skilled agricultural occupations have been included in a single sub-major group in Major Group 3 Technicians and Trades Workers. This will enable better analysis of the agricultural sector of the New Zealand labour market as there is a clear separation of farmers from the farm workers. No new agricultural occupations have been included in the classification, other than those specific to the Australian economy eg Sugar Cane Grower, Cotton Grower.

\section{Information and Communication Technology (ICT)}

ICT is one of the fastest growing and changing areas for the occupation classification. For the ANZSCO project, an ICT Occupational Nomenclature Working Group was established in Australia. Its role was to identify ICT specific occupations and advise the project team on a classification structure that reflected the real world. Some of the issues faced in dealing with ICT occupations for the ANZSCO classification have been the need to ensure that the classification structure and titles:

- should be easily understandable by employers and jobseekers;

- represent occupations which are large enough to be statistically valid for labour market analysis;

- reflect the actual usage of occupations as evidenced by newspaper or internet advertisings; and

- remain meaningful for several years, while have the capacity to incorporate new titles as they emerge. 
The work done by the ICT Nomenclature Group has resulted in two sub-major groups being included in ANZSCO covering ICT Professional occupations and ICT Support occupations.

\section{Supervisors, Trainees and Apprentices}

As with NZSCO, Supervisors, Trainees and Apprentices will be classified to the occupation in which they are supervising, training or an apprentice to. In some instances where there is significant user demand, supervisor and/or trainee occupations may be separately identified in the classification structure.

\section{Country-Specific Occupations}

ANZSCO will feature occupations that are specific to each country. Obvious examples would be Sugar Cane Grower, Cotton Grower, Bookmaker for Australian needs. For New Zealand needs occupations such as Kaiako Kura Kaupapa Mäori, Kaiawhina (Hauora) are examples.

\section{Producing a Relevant Real-World Classification}

The challenge in developing a classification is to maintain historical comparability while providing an accurate framework to continue reporting on the entity being classified. An occupation classification has to reflect changes in society and be dynamic enough to cater for emerging occupations.

The development of ANZSCO has significantly benefited from the input of stakeholders and users in identifying current terminology for occupation titles. This input is really the only way that a statistical agency can keep abreast of real world changes. Statistics NZ and the ABS plan to more regularly update the classification, via both agencies websites, to take account of the dynamic changes in the labour market.

\section{References}

Australian Bureau of Statistics. (1997). Australian Standard Classification of Occupations (ASCO) Second Edition, Canberra 1997

Statistics New Zealand (1999). New Zealand Standard Classification of Occupations (NZSCO), Wellington, 2001 